\title{
Especificidade das descargas do órgào elétrico em espécies de Gimnotóides simpátricos do rio Negro.
}

\author{
Walter Heiligenberg (') \\ Joseph Bastian $\left({ }^{2}\right)$
}

\begin{abstract}
Resumo
Descargas do órgão elétrico (EODs) de seis espécies simpátricas, habitantes de lama de gimnotóides do rio Negro ocupam áreas não sobrepostas de picos de freqüência e taxa de repetição. Como os eletrorreceptores são conhecidos como os mais sensiveis dentro do pico de freqüência da espécie, a evolução da EODs com espectros específicos para espécie minimizaria a conversaçāo cruzada das espécies na comunicação social.
\end{abstract}

\section{INTRODUÇÃo}

Os gimnotóides elétricos são muito abundantes em águas da Amazônia. O sentido elétrico deles permite comunicação social através das descargas do órgão elétrico típicas para as espécies (cf. Hopkins, 1972a, b; 1974a, b, c) e a "eletrolocalização" de objetos no ambiente ao redor (Lissmann, 1958; Bullock, 1968; Heiligenberg, 1977). Desta maneira, os gimnotóides desfrutam de uma vantagem especial em águas de pouca visibilidade e, por serem mais ativos durante a noite, minimizam a predação por inimigos visuais (Cf. Hopkins, 1972a).

Os peixes elétricos são geralmente classificados com relação as suas descargas do órgão elétrico (EODs) como espécie do tipo pulso ou do tipo onda (Cf. Lissman, 1958; Bullock, 1974; Hopkins, 1974a). As espécies do tipo pulso disparam o órgão elétrico em discretos pulsos que são curtos comparados com o intervalo entre pulsos. A taxa de repetição de EOD comumente progride em condições novas. Espécies do tipo onda disparam o órgão elétrico, em uma maneira, em forma de onda contínua e em freqüências altamente estáveis. Dos gêneros e famílias mencionados neste texto, são do tipo pulso: Hypopomus, Hipopy- gus, Steatogenys, Rhamphichthys, Gymnorhamphichthys; os tipos onde são Sternopygus, Eigenmannia, Rhabdolichops, Distocyclus e todos os Apternotídeos.

As espécies dos gêneros Hypopomus e Hypopyqus vivem em fundos lamacentcs e em fundos com folhas submersas de águas rasas. Eles são excelentemente camuflados por vários padrões de cores que, face à sua considerável variabilidade, torne difícil distinguir, com exatidão, as espécies somente com base na sua aparência visual. Contudo, como será demonstrado neste trabalho, todas as espécies podem ser prontamente distinguidas com base em sua atividade eéltrica que, provavelmente como uma conseqüência de seu papel na comunicação social, mostra considerável variabilidade entre espécies, porém constância dentro de cada espécie.

O presente trabalho centraliza-se em 5 espécies de Hypopomus e uma espécie de Hypopygus entre as quais todas vivem simpatricamente em substratos lamacentos do sistema do rio Negro (Tabela 1). Nenhuma informação útil pode ser obtida da maioria da literatura mais antiga sobre peixes amazônicos, tais como Ellis (1911), para identificar estas espécies. Com a gentil assistência do Dr. F. Mago Leccia as espécies de Hypopomus, que são numeradas de $\mathrm{H} .1$ a $\mathrm{H} .5$ neste trabalho (Cf. fig. 1) foram experimentalmente identificadas como se segue :

H.1 é Hypopomus brevirostris, descrita por Steindachner (1868) como Rhamphichthys brevirostris. Esta espécie é idêntica em aparência e comportamento elétrico à espécie do Suriname que erroneamente foi denominada $\mathrm{Hy}$ popomus artedi (Hopkins \& Heiligenberg, s.d.);

(1) - Scripps Institution of Oceanography, UCSD, La Jolla, California.

(2) - Dept. of Zoology, U. of Oklahoma, Norman, Oklahoma. 
TABELA 1 - Gimnotóideos do tipo pulso do rio Negro

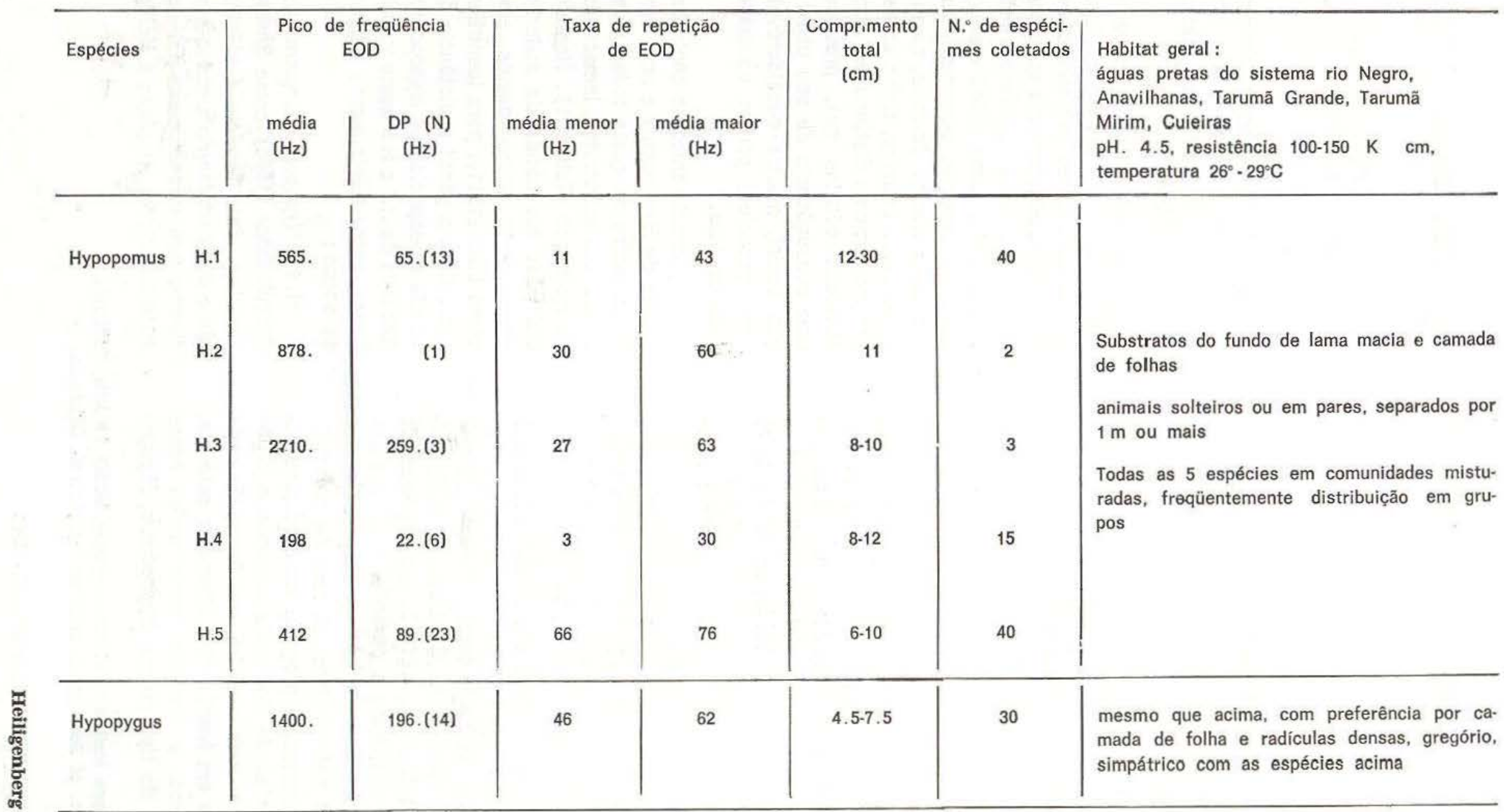


H.2 é Hypopomus beebei, como descrito por Schulz (1949) e também referida do Suriname (Hopkins \& Heiligenberg, s.d.);

H.3 é Hypopomus artedi, provavelmente a espécie descrita como Rhamphichthys artedi por Kaup (1856). Esta espécie é idêntica em aparência e comportamento elétrico à espécie do Suriname que erroneamente foi denominada Hypopomus brevirostris (Hopkins \& Heiligenberg, s.d.);

H.4, da qual espécimes maduros de ambos os sexos foram coletados, é uma nova espécie que logo será descrita por Mago Leccia;

H. 5 é Hypopomus bilineatus, descrita como Microsternarchus bilineatus por Fernando Yepes (1968).

A única espécie de Hypopygus é idêntica à Hypopygus lepturus do Suriname (Hoedeman, 1962: Nijssen \& Isbrücker, 1972), embora seu comportamento elétrico seja ligeiramente diferentes. (Ver resultados) .

Os espécimes de todas as espécies estão prescrvados no INPA/Manatis, Brasil. Os respectivos códigos são dados na legenda da fig. 1.

\section{MÉTodos}

Águas rases dos rios Negro e Solimões foram estudadas em duas visitas ao INPA, em Manaus-Brasil, em fevereiro-março e novembrodezembro de 1976, respectivamente. Um total de 4 semanas foi gasto em diferentes partes do rio Negro, isto é, Anavilhanas, rios Cuieiras. Tarumã-Mirim e Tarumã-Grande. Somente 3 dias foram gastos durante dezembro no lago Janauacá/Solimões .

Os animais foram descobertos com um "detector de peixes" especial, um par de eletrodos colocados na ponta de uma vara, aproximadamente $15 \mathrm{~cm}$ separados um do outro. $\mathrm{O}$ sinal destes eletrodos foram diferencialmente gravados e audioamplificados. As descargas do órgão elétrico (EODs) eram, desta maneira, cietectadas acusticamente e, com algum treino, as espécies podiam comumente ser identificadas com base neste sinal somente. Dependendo da espécie e tamanho do espécime, os ani- mais podiam ser detectados a uma distância de uns poucos decimetros até uns poucos metros. Os eletrodos, colocados na ponta de uma vara, permitia uma rápida e fácil sondagem dos substratos do fundo, buracos e sistemas de raizes imperetráveis, enquanto o pesquisador viajava em um barco ou vadeava e nadava na água.

Após a localização de um peixe ter sido determinada pela zeragem sobre o centro da "fonte de som", uma quantidade suficientemente grande de substrato era raspada com uma rede em mão. O conteúdo da rede era então testado com o mesmo detector, o material do substrato cuidadosamente removido, enquanto um controle contínuo da presença de peixes era feito até que ele pudesse ser encontrado visualmente. O peixe era capturado com uma chance de mais de $90 \%$ na primeira tentativa e com certeza em tentativas subseqüentes se ele não tivesse saído mais que alguns metros e pudesse ser novamente localizado. Em algumas ocasiões, o peixe desligava sua EOD em resposta a súbitos distúrbios, mas recomeçava sua atividade elétrica dentro de menos de um minuto depois. A captura de peixe foi dificultada em áreas destruídas por galhos submersos e denso sistema de raízes, requerendo grande trabalho para limpar o substrato do fundo em tais casos.

Em quase todas as ocasiões todos os peixes elétricos em uma dada área eram capturados por sondagem sistemática de toda a área do fundo para estimar-se a distribuição da es" pécie. O número total de espécimes capturados é dado na coluna 7 da tabela 1 e grosseiramente reflete abundância da espécie no habitat particular.

Os EODs de muitos espécimes foram gravadios em pequenos aquários, cheios com água de seus habitats, com o eletrodo positivo em frente da cabeça do animal e o eletrodo negativo atrás da ponta da cauda. O sinal da EOD era amplificado por um Grass P 15 na máxima faixa de freqüência e mostrado em um osciloscópio ou gravado em um gravador de fita Uher 4200. Consideráveis variaçōes na forma da EOD são encontradas se os eletrodos de gravaçãr são colocados em diferentes arranjos perto da superfície do corpo do animal (Cf. 
Bastian, 1977). Isto é devido ao fato de que órgão elétrico em algumas espécies não é acio. nado em estrita sincronia e que o escoamento local em seu isolamento causa diferentes padrões de corrente ao longo da superfície do corpo do animal. Medidas da cabeça $(+)$ à cauda foram usadas neste trabalho como um método padronizado para comparar espécies. Espécimes de todas as espécies foram transportados vivos para o laboratório para posteriores estudos de comportamento e eletrofisiológicos. Suas EODs não mudaram em condições de aquário que imitava os valcres de $\mathrm{pH}$ e resistência específica de seus habitats naturais tanto quanto pcssivei. A amplitude e fases de espectros apresentadas na fig. 2 foram obtidas de EODs gravadas e digitadas em linha por um computador PDP 11/40, com uma taxa de amos tragem de $50 \mathrm{KHz}$ e precisão de 12 "bit". EODs únicas eram processadas por análise de captura transitória de Fourier, com a EOD centralizada em torno do tempo $=0$.

Em um sistema de gravação padronizado, as EODs de um determinado indivíduo são altamente estereotipados. Elas variam pouco entre indivíduos de uma determinada espécie e assim fornecem um palpite seguro para a identificação de espécies (Cf. figs. 3 e 4). No entanto espécimes machucados podem apresentar EODs distorcidas que gradualmente se normalizarão enquanto o animal se recupera e se regenera. Todas as EODs apresentadas neste trabalho foram gravadas de espécimes intactos.

\section{RESULTADOS}

Cinco espécies de Hypopomus, referidas como H.1 a H.5, e uma espécie de Hypopygus vivem simpatricamente em fundos lamacentos de águas negras do sistema do rio Negro. Em contraste com Hypopomus, que geralmente também ocorre em lama livre de quantidades substanciais de folhas submersas, Hypopygus só ocorre em áreas cobertas com camadas de folhas e freqüentemente agregados em densas radículas. A fig. 1 mostra fotografias de espécimes vivos destas espécies, e a fig. 2 mostra suas EODs e espectro Fourier. A freqüência espectral com a mais alta amplitude será refe-

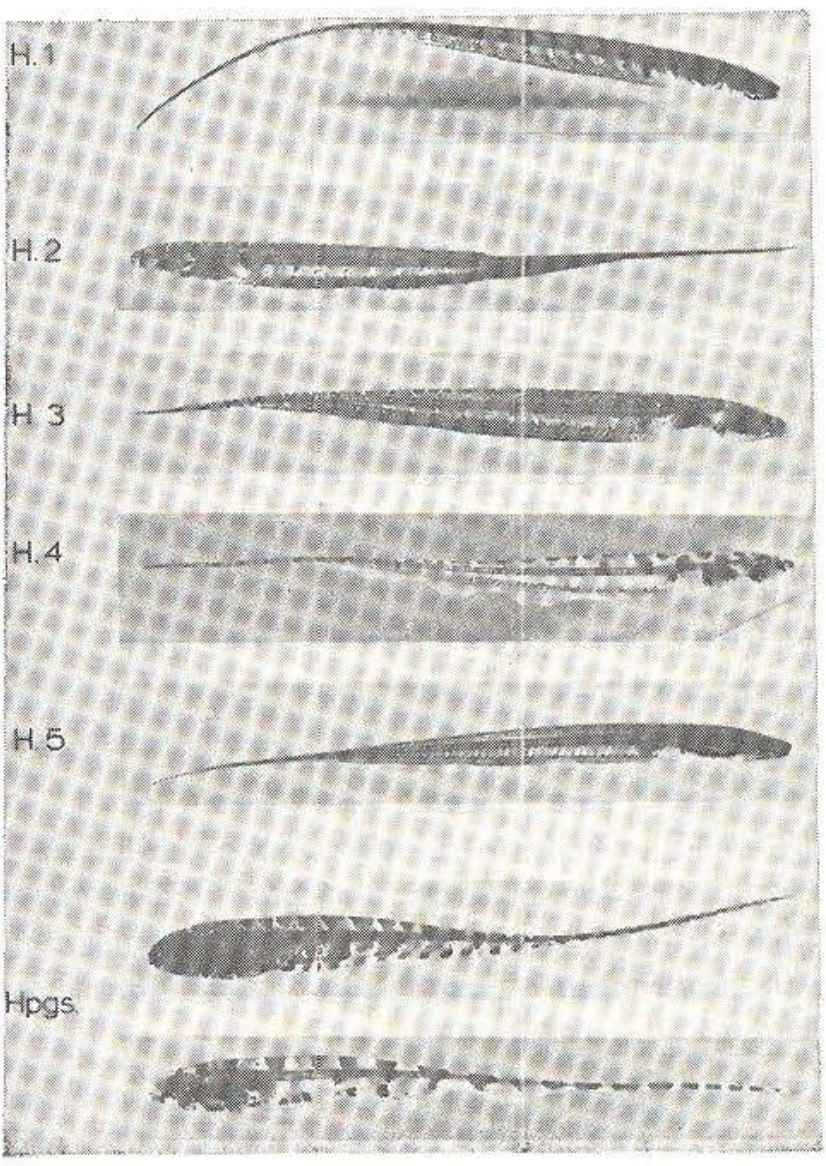

Fig. 1 - Fotografias de espécimes vivos de cinco espécies de Hypopomus, H.1 a H.5, e de Hypopygus lepturus (Hpgs). Números do catálogo do INPA são dados em parênteses: H.1) - Presumivelmente Hypopomus brevirostris, comprimento total $14 \mathrm{~cm}$. Faixas largas de marrom acinzentado $\mathrm{em}$ fundo amarelado. Lado anterior esbranquiçado (INPA 1976, 11.30.1); H.2) - Hypopomus beebel, comprimento total $11 \mathrm{~cm}$. Listras finas verticais protas em tundo bege amarronzado. Lado torna-se enegrecido, se o animal vive em substrato escuro (INPA 1976, 11.30.2). Observar cauda regenerada; H.3) - Provavelmente Hypopomus artedi, comprimento total $10 \mathrm{~cm}$. Coloração marrom bege clara com pontilh đdo grosseiro escuro no dorso e lados sarapintados. Corpo menos transparente e pico de freqüência mais alta de EOD diferença H.3 de H.5 (INPA 1976, 11.30.3); H.4) - Espécie nova, comprimento total $10 \mathrm{~cm}$. Corpo esbranquiçado semitransparente com largas listras enegracidas, e manchado. Padrões escuro poliao se o animal é mantido em fundo claro (INPA 1976, 11.30.4); H.5) - Hypopomus bilineatus, comprimento total $9,5 \mathrm{~cm}$. Corpo acınzentado semitransparente com vistoso pontilhado enegrecido e no dorso da maioria cos individuos. Uma tina linha preta corre paralela em cada lado do dorso do animal, dai seu nome "bilineatus". Corpo mais transparente e delgado e pico de freqüência de EOD menor distingue H.5 de H.3 [INPA 1976, 11.30.5); Hpgs] - Hypopygus lepturus. Espécime superior: comprimento total $7 \mathrm{~cm}$. Listagem marrom escuro irregular em tundo marrom claro. Alto. corpo em forma de faca e filamento caudal tino e longo alem do fim do nadadeiro anal distingue o gënero Hypopygus do gênero Hypopomus que é mais em forma de verme. Espécime interior: comprimento total $5 \mathrm{~cm}$. Provavelmente forma jovem da forma superior. Listagem mais distinta e separada que na forma superior. Mesma EOD (INPA 1976, 11.30.6). 


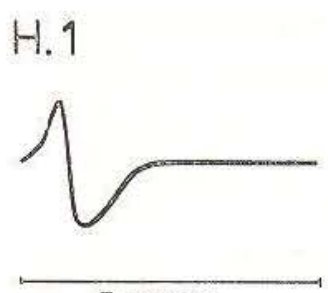

$5 \mathrm{msec}$
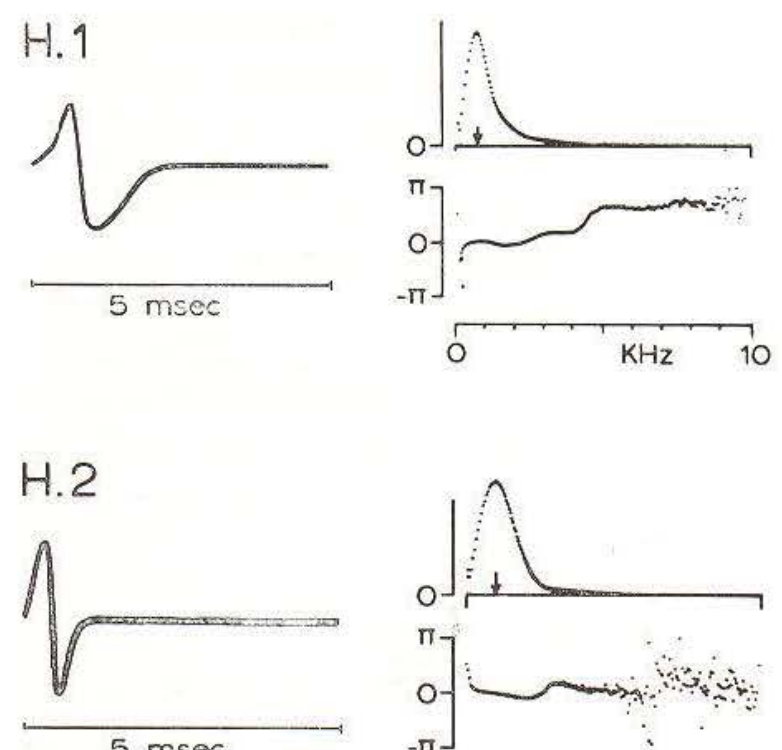

$5 \mathrm{msec}$
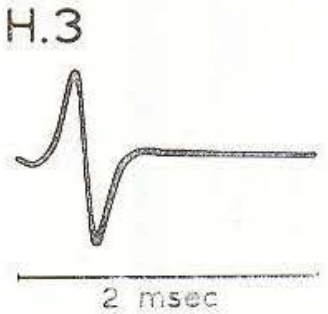
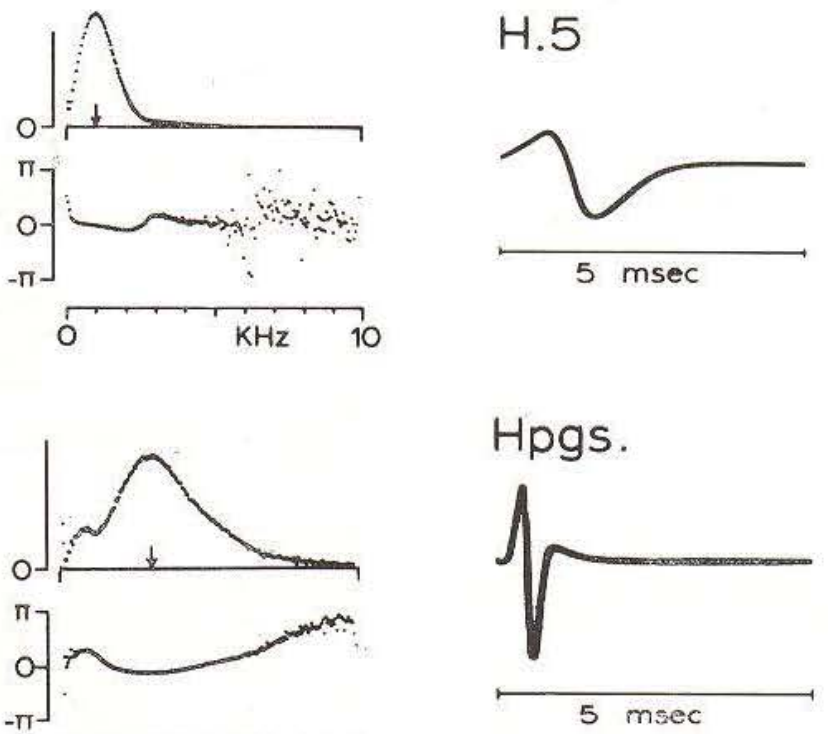
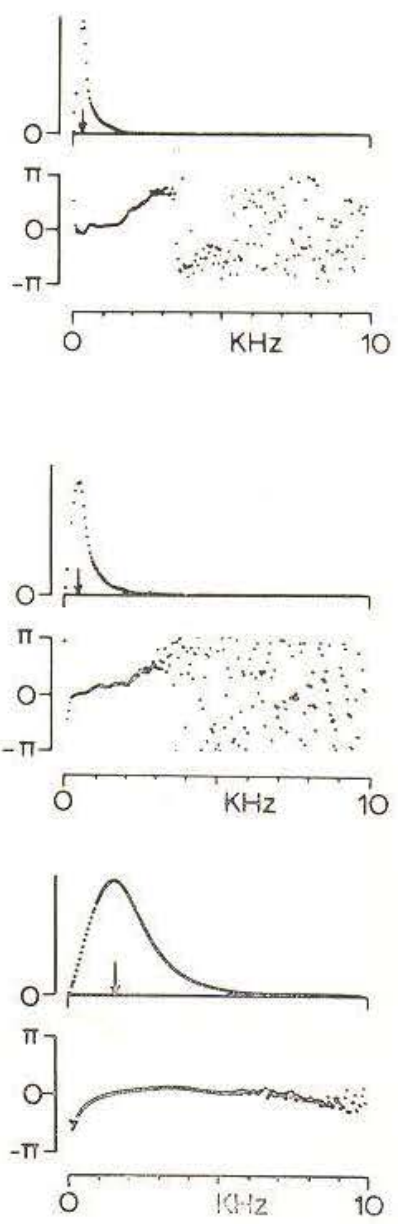

Fig. 2 - Descargas do orgão elétrico (EODs) e seus espectros Fourier das espécies de Hypopomus, H.1 e H.5, e de Hypopygus lepturus (Hpgs). Cada diagrama mostra EOD e tempo de calibração na esquerda (polaridade pos tiva, cabeça, para cima) e espectro Fourier da EOD na direita, com o espectro superior sendo o espectro de amplitude linear (seta vertical indica o pico de freqüência) e o espectro inferior sendo a função de fase.

rida como "pico de freqüência" nas descrições subseqüentes. A tabela 1 resume várias características destas espécies.

Para demonstrar o grau de variabilidade da EOD dentro de uma determinada espécie, EODs de seis espécimes de $\mathrm{H} .1$ e $\mathrm{H} .5$ respectivamente, estão mostradas na fig. 3. As EODs de H. 5 foram as mais variáveis de todas as espécies estudadas.

A espécie de Hypopygus do rio Negro parece-se muito com Hypopygus lepturus do Suriname (Hoedeman, 1962). Suas EODs são muito semelhantes na forma. Contudo, elas diferem significativamente com respeito a seus picos de freqüência que dão em média 1400 $\mathrm{Hz}(E P=195)$ no rio Negro e $2440 \mathrm{~Hz}(E P=73)$ no Suriname (Hopkins \& Heiligenberg, s.d.).
Diferenças tão drásticas não foram encontradas entre as EODs dos representantes das espécies de Hypopomus brasileiros e surinamenses, H.1, H.2, e H.3 (Cf. introciução para suas identificações).

As espécies habitantes de lama do rio $\mathrm{Ne}$ gro diferem não somente com respeito a seus picos de freqüência mas também em suas taxas de repetições da EOD que cobrem diferentes amplitudes de baixas taxas, gravadas quando o animal está descansando, à altas taxas, gravedas durante grande atividade. A fig. 4 resume estes dados e demonstra que estas 6 espécies simpátricas estão organizadas em áreas não sobrepostas do parâmetro espacial bidimensio nal. A significância desta característica con: respeito à comunicação social será discutida mais adiante. 

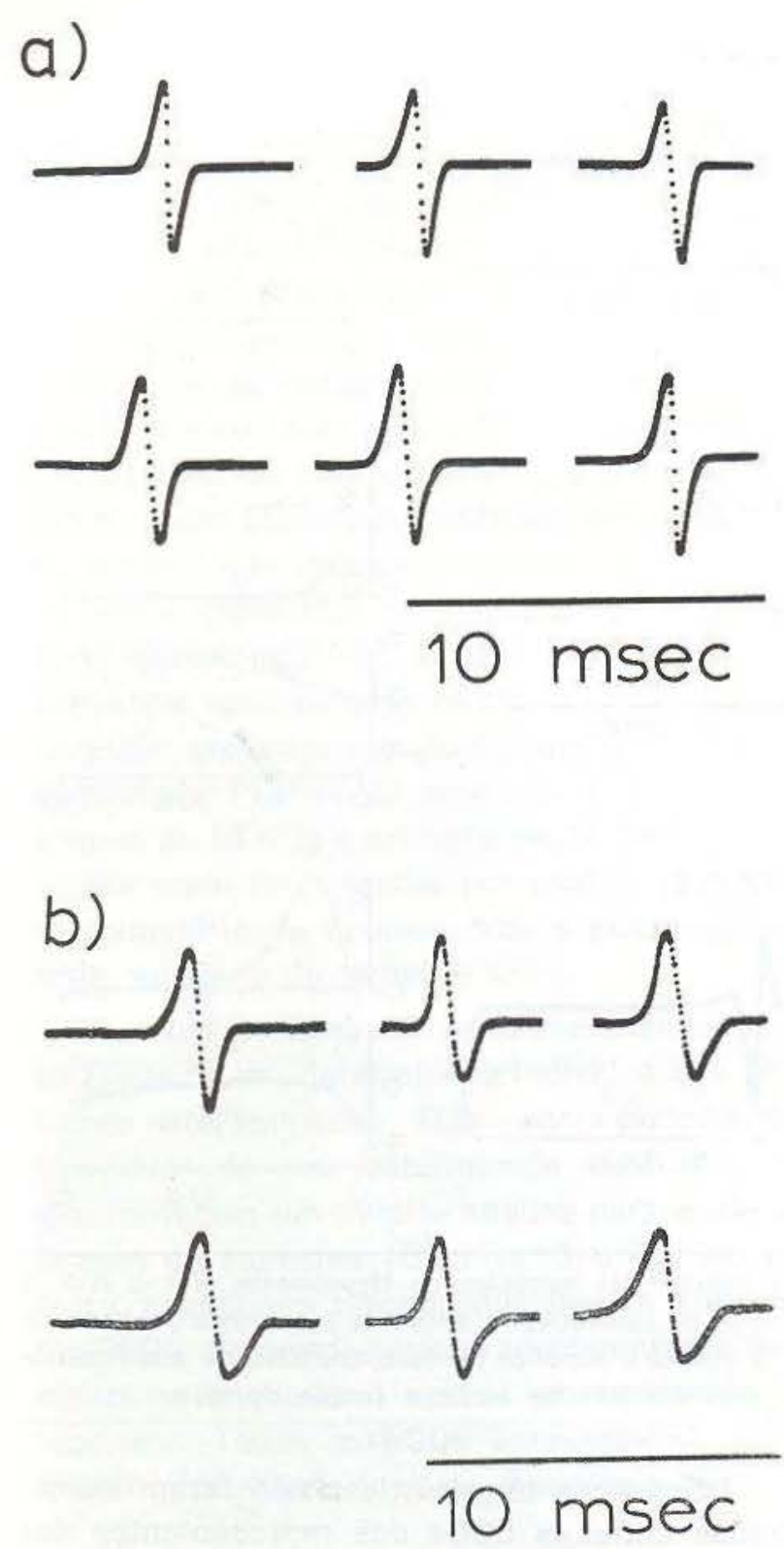

Fig. 3 - EODs únicas de seis indivíduos de Hypopomus H.1(a) e de seis individuos de Hypopomus H.5(b) para mostrar a variação interindividual. Variações são maiores em H.5 (Cf. tamanho do desvio padrão do pico de freqüência como expressa pela largura das colunas na fig. 4)

Nenhuma outra espécie de gymnotoideo foi encontrada nestes habitats durante o dia. No entanto, à noite, muitas outras espécies, tais como Steatogenys e várias espécies com os EODs do tipo onda, como Eigenmannia Sternopyguis e vários apteronotídeos invadiam estas águas. Seus rápidos dcslocamentos tornavam a captura com rede em mão impossível.
Uma espécie de gymnotoideo adicional do rio Negro, Gymnorhamphichthys hypostomus, foi encontrada enterrada em praias de areia durarite o dia. Nenhuma outra espécie compartilhava deste habitat durante o dia, ao passo que numerosas espécies passavam por lá, à noite. A ecologia e comportamento desta espécie foi amplamente estudado por Schwassmann (1976). Esta espécie parece ser idêntica à do Suriname (Hopkins \& Heiligenberg, s.d.) .

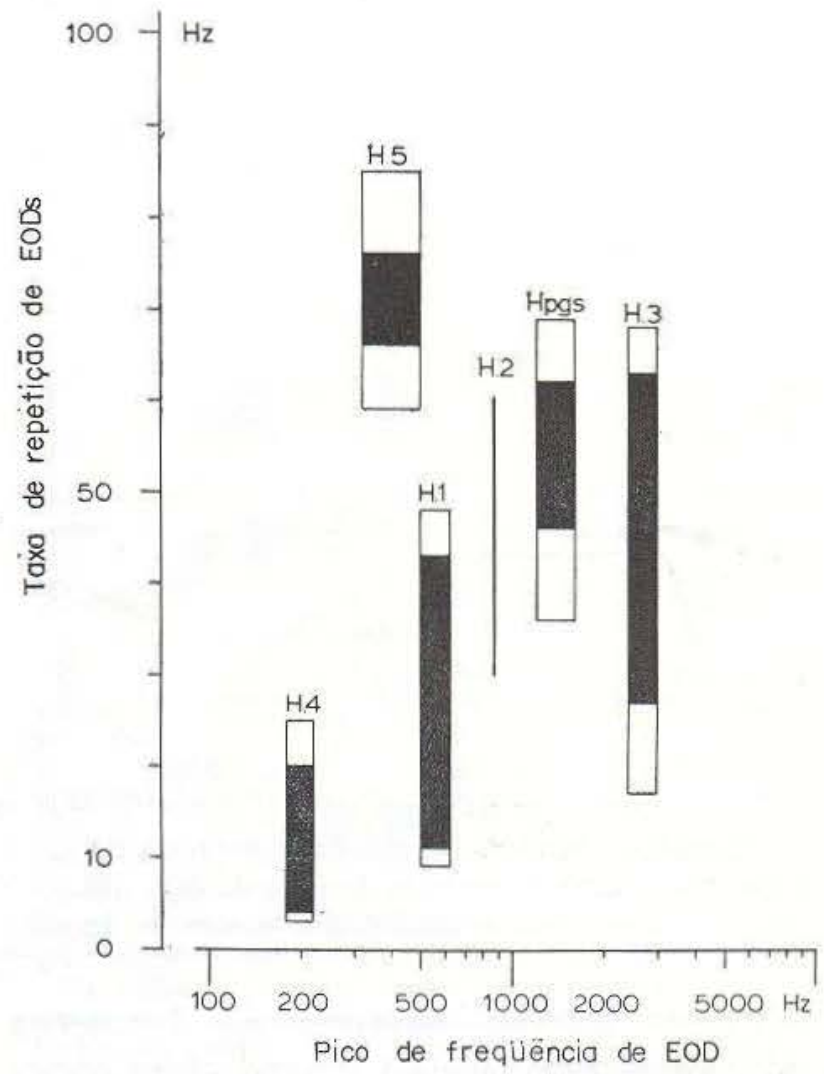

Fig. 4 - Taxas de repetiçăo e picos de freqüências de seis gimnotoideos simpátricos habitantes de fundo lamacento do rio Negro, espécies de Hypopomus, H.1 e H.5, e Hypopygus lepturus (Hpgs). A amplitude do desvio padrão para quaisquer dos lados do pico de freqüência média é indicada pela largura de cada coluna preta. As pontas inferior e superior de cada coluna preta indicam as taxas de EOD médias menores e maiores respectivamente. As colunas cobertas em qualquer parte das colunas pretas indicam amplitude de um desvio padrão além da respectiva taxa de EOD média. Somente um espécime de $\mathrm{H} .2$ estava disponível. O traço vertical negro indica seu pico de freqüência e varia de menor a maior taxa de EOD. Os números de individuos de H.1, H.3, H.4, H.5 e Hpgs. medidos foram 13, 3, 6,23 e 14 respectivamente. Observe-se a não sobreposição de características de EOD nestas espécies simpátricas. 


\section{Discussão}

Hopkins $[1972,1974)$ demonstrou a significância das EODs típicas para espécies no contexto da comunicação social. Ele demonstrou que as freqüências fundamentais de EOD de três espécies simpátricas na Guiana, com EODs contínuas do tipo onda, denominadas Sternopygus macrurus, Eigenmannia virescens e Apternotus albifrons ocupavam diferentes faixas de freqüência e que eletrorreceptores eram mais sensiveis na freqüência fundamental da EOD respectiva da espécie (Hopkins, 1976). Bastian $(1976,77)$ e Hopkins \& Heiligenberg (s.d.) também deram evidência que os eletrorreceptores de gymnotoideos com EODs do tipo pulso são sintonizados no pico de freqüência da EOD da espécie e que os animais devem assim ser mais sensiveis às suas específicas descargas. Três espécies de Hypopomus simpátricos no Suriname, $H$. artedi, $H$. beebei e $H$. brevirostris, mais provavelmente idênticas a H. $3, \mathrm{H} .2$ e H.1, respectivamente, neste trabatho, foram comprovadas ter diferentes picos de freqüência e eletrorreceptores sintonizados adequadamente (Hopkins \& Heiligenberg, s.d.). Os dados apresentados para seis espécies sim- pátrices do tipo pulso do rio Negro (Fig. 4) sugerem uma situação semelhante. Estudos eletrofisiológicos são necessários parı determinar as características de freqüência de resposta de eletrorreceptores nestas espécies. Estes dados indicarão em que intensidade a EOD de uma dada espécie será perceptível por outras espécies, em particular, quanta "conversa cruzada" pode ocorrer entre as espécies H.1 e H.5 de Hypopomus. Porém mesmo se os pi$\cos$ de freqüência destas duas espécies não estão separados suficientemente para evitar conversação cruzada entre as espécies suas claras diferenças na taxa de repetição de EOD fornecem uma sugestão adicional para a identificação das espécies. Experimentos de comportamento ainda tem que demonstrar a significância das EODs típicas da espécie para a comunicação social em Hypopomus e Hypopygus.

Um desafio mais óbvio para a suposição de que espécies simpátricas exploram diferentes faixas de freqüência foi encontrado durante uma visita de três dias no lago de Janauacá que é parte do sistema Solimões (água branca, $\mathrm{pH} 7$, resistência $10 \mathrm{KOhm} \mathrm{cm}$ ). Pescadores do INPA capturaram muitos gymnotoideos com

TABELA 2 - Gimnotóideos do tipo onda do lago Janauacá/Solimões

\begin{tabular}{l|c|c|c|}
\hline Espécies & $\begin{array}{l}\text { Menor e maior freqüência fundamental de EOD } \\
\text { em n individuos }\end{array}$ & $n$ \\
\hline Sternopygus macrurus & 60 a $150 \mathrm{~Hz}$ & 20 \\
Eigenmannia virescens (?) & 430 a $660 \mathrm{~Hz}$ & \\
Distocyclus conirostris & 180 a $250 \mathrm{~Hz}$ & 11 \\
Rhabdolichops troscheli & 580 a $1000 \mathrm{~Hz}$ & 3 \\
\hline Adontosternarchus saxi & 950 a $1250 \mathrm{~Hz}$ \\
Adontosternarchus spec. & 710 a $1330 \mathrm{~Hz}$ & 20 \\
Apteronotus anas & 1080 a $1250 \mathrm{~Hz}$ & 5 \\
Apteronotus spec. & 1080 a $1170 \mathrm{~Hz}$ \\
Sternarchorhynchus oxyrhynchus & 1400 a $1800 \mathrm{~Hz}$ \\
Porotergus terminalis & 1280 a $1700 \mathrm{~Hz}$ & 3 \\
\hline
\end{tabular}


uma grande malhadeira, com aproximadamente $40 \mathrm{~m}$ de comprimento e $12 \mathrm{~m}$ de altura, com tamanho de malha de $0.5 \mathrm{~cm}$, durante excursões noturnas em águas abertas do lago. Mesmo que a maioria dos espécimes estivessem, fericios, eles viveram o suficiente para permitir a gravação de EOD na maioria dos casos. Dois gymnotóideos do tipo pulso, Rhamphichthys e Steatogenys e muitas espécies do tipo onda, catalogados na tabela 2, foram capturados desta maneira. Como pode ser lido desta tabela, Sternopygus, Distocyclus, Eigenmannia e Rhabdolichops mostam pequena sobreposicão nas suas freqüências de EOD fundamental e assim seguem o padrão descrito por Hopkins (1976) para espécies simpátricas do tipo onda na Guiana. Contudo, considerável sobreposição nas freqüências de EOD é encontrada entre os apternotídeos, com, pelo menos, quatro espécies cobrindo a mesma faixa de freqüência, 1000 a $1200 \mathrm{~Hz}$.

Nada é conhecido sobre os hábios reprodutivos destas espécies, especialmente se eles se reproduzem em diferentes habitats ou se aumentam o reconhecimento da espécie por modulação específica da espécies de suas freqüências de EOD durante encontros de combate ou corte. O lago de Janauacá face à sua abundância de gymnotoideos, pode ser uma área mais adequada para estudar os problemas de identificação de espécies em peixes elétricos.

\section{AGRADECIMENTOS}

Somos muito grato ao INPA em Manaus/ Brasi! pela generosíssima assistência em nossa pesquisa de campo. Este trabalho foi financiado pela subvenção da NSF BMS 74-18640 dada a W. H. e uma subvenção de viagem dada a J. B. pela University of Oklahoma. Tom Uter gentilmente construiu nosso detetor eletrônico de peixe. Carl Hopkins deu valiosa opiniāo na preparação deste manuscrito. Francisco Mago Leccia generosamente auxiliou na identificação das espécies.

\section{SUMMARY}

Electric organ discharges (EODs) of six sympatric, mud-dwelling gymnotoid fish species of the Rio Negro occupy non-overlapping ranges of peak power frequen- cies and repetition rates (fig. 4). Since electro-receptors are known to be most sensitive at the species' peak power frequency the evolution of EODs with species specific spectra should minimize species "cross talk" in social communication.

\section{REFERENCIAS IIBLIOGRÁFICAS}

BASTIAN, J.

1976 - Frequency response characteristics of electroreceptors in weakly electric fish (Gymnotoidei) with a pulse discharge. J. Comp. Physiol., 112: 165-180.

1977 - Variation in the frequency response of electroreceptors dependent on receptor location in weakly electric fish (Gymnotoidei) with a pulse discharge. (In preparation).

BULLOCK, T.H.

1968 - Biological sensors. In: Vistas in Science. Albuquerque: Univ. of New Mexico Press.

1974 - General introduction to handbook of sensory Physiology, 111/3. Ed. A. Fessard. Berlin, Springer Verlag.

ELLIS, M.M.

1911 - The Gymnotoid cels of tropical America. Memoirs of the Carnegie Museum, 6 (3): 109-195.

FERNANDO YEPES

1968 - Contribucion al conocimiento de los peces gymnotiformes. Evencias, 20.

HEILIGENBERG, W.

1977 - Principles of electrolocation and jamming avoidance in electric fish. In: Studies of Brain Function. v. 1.

HOEDEMAN, J.J.

1962 - Notes on the ichthyology of Surinam and other Guianas, 9 and 11. Bull. of Aquatic Biol., 3: 26, 53-60 and 3: 30, 97-108.

HOPKINS, C.D.

1972a - Patterns of electrical communication among gymnotoid fish. Ph.D. Theses. Rockefeller University, N.Y.

$1972 b$ - Sex differences in electric signaling in an electric fish. Science, 176: 1035-37.

1974a - Electric communication: Functions in the social behavior of Eigenmannia virescens. Behavior, 50: 3-4, 270-305.

1974b- Electric communication in fish. American Scientist, 62: 4, 426-437.

$1974 \mathrm{C}$ - Eletric communication in the reproductive behavior of Sternopygus macrurus (Gymnotoidei) Z. Tierpsychol., 35: 518-535. 
1976 - Stimulus filtering and electroreception: tuberous electroreceptors in three species of gymnotoid fish. J. comp. Physiol., 3: 171. 207.

HOPKINS, C.D. \& HEILIGENBERG, W.

s.d. - Electrical Communication by Gymnotoid fish from Coastal Surinam (in prep.).

KAUP

1856 - Catalogue of apodal fish in the collection of the British Museum. London, p. 128-129.

LISSMANN, H.W.

1958 - On the function and evolution of electric organs in fish. J. exp. Biol., 35 (1): 156-191.

NIJSSEN, H. \& ISBRÖCKER, I.J.H.

1972 - Hypopygus lepturus, a litlle known d'warf gymnotoid fish from South America. Zool. Mededelingen, 47: 160-176.
SCHULTZ, L.P.

1949 - A further contribution to the ichthyology of Venezuela. Proc. US Nat. Mus., 99: 1.211.

SCHWASSMANN, H.O.

1976 - Ecology and taxonomic status of different geographic populations of Gymnorhamphi chthys hypostomus Ellis. Biotropica, 8 (1): 25-40.

STEINDACHNER, F.

1868 - Die Gymnotidae des K.K. Hof - Natura'ienkabinets zu Wien. Sitzb. der K. Akademie der Wissenschaften zu Wien, 58 (1): 249. 264.

(Aceito para publicação em 08/07/80) 